\title{
Effectivity comparison between aspirin, propolis, and bee pollen as an antiplatelet based on bleeding time taken on mice
}

\author{
Sake Juli Martina ${ }^{1,2, *}$, Muhammad Luthfi $^{1}$, Pradeepa Govindan ${ }^{1}$, and Arlinda Sari Wahyuni ${ }^{3}$ \\ ${ }^{1}$ Department of Pharmacology and Theraupeutics Faculty of Medicine, Universitas Sumatera Utara, Jl. dr. Mansur No.5 Kampus USU, \\ Medan, Indonesia \\ ${ }^{2}$ Universitas Sumatera Utara Hospital, Jalan dr. T. Mansur No.66 Kampus USU, Medan, Indonesia. \\ ${ }^{3}$ Department of Public Health, Faculty of Medicine, Universitas Sumatera Utara, Jl. dr. Mansur No.5 Kampus USU Medan, Indonesia
}

\begin{abstract}
The use of standard antiplatelet therapy for cardiovascular disease patients has many side effects. This study aims to determine the effectiveness of Propolis and Bee Pollen, two bee products, as antiplatelet and in comparison with Aspirin. This is an experimental study with posttest only control group design. The samples were 32 mice, divided into 4 groups: placebo, administration of aspirin $(10.4 \mathrm{mg} / \mathrm{kg}$ bw/day), Propolis (65 mg/kg-bw/day), and Bee Pollen (68 mg/kg-bw/day). The study was conducted for 12 days and the suspensions were given orally. The bleeding time was then measured using tail-bleeding technique. The data collected was bleeding time in seconds. All samples completed the study. The mean bleeding time for placebo, Aspirin, Propolis and Bee Pollen groups were 106.1, 442.9, 310.1, and 203 in seconds respectively. ANOVA and Bonferroni tests showed a significant difference between Propolis and placebo groups $(p=0.003)$, no difference between Propolis and Aspirin groups $(p=0.100)$, no difference between Bee Pollen and placebo groups $(\mathrm{p}=0.442)$, and a significant difference between Bee Pollen and Aspirin groups $(\mathrm{p}=0.000)$. Administration of Propolis in mice showed prolongation of bleeding time while Bee Pollen did not prove to have antiplatelet effects.
\end{abstract}

\section{Introduction}

Hemostasis is the sequence of events of the body's response to stop a bleeding. When blood vessels are damaged or ruptured, the hemostasis response must be immediate, localized to the damaged area, and carefully controlled for the response to be effective. There are three main mechanisms in the hemostasis process: vascular spasm, platelet plug formation, and blood clotting. If these three mechanisms work perfectly, then hemostasis can stop the bleeding that occurs [1].

Hemostasis in general plays an important role in helping to maintain the condition of body fluid homeostasis, especially to prevent the occurrence of large amounts of blood loss in the event of damage or rupture of the blood vessels. However, if it occurs abnormally, the process of hemostasis, especially the mechanism of blood clotting (blood clotting) can cause a fatal disorder. Blood clots can sometimes form in the cardiovascular system without damage to blood vessels (usually in the veins). This condition is called thrombosis. The lump itself, called the thrombus, can block the flow of blood to the blood vessels with a smaller diameter. This will be fatal if the inhibited flow is the blood vessel leading to vital organs [1].

Thrombosis is common in patients with a history of heart disease and abnormalities in blood vessels, for example in patients with Transient Ischemic Attack
(TIA), stroke, myocardial infarction, Coronary Heart Disease (CHD), which can be categorized as CVD (cardiovascular disease). CVD is one of the biggest causes of death in the world, with 17.5 million deaths or about $46 \%$ of all deaths from Non Communicable Diseases (PTM) in 2012. In Indonesia alone, death rate from CVD reached 371 deaths per 100,000 in 2012 [2].

Provision of antiplatelet therapy is effective against the treatment of patients with CVD in both short-term and long-term administration [3]. In addition, administration of antiplatelet therapy may reduce the incidence of CVD by $25 \%$ in high-risk patients [4].

Aspirin as one of the antiplatelet drugs has been approved by the FDA for use as primary CVD prophylaxis [5]. According to the study, aspirin oral administration with a dose of $100 \mathrm{mg}$ in a single dose is sufficient to inhibit platelet aggregation [3]. Aspirin, or Acetylsalicylic acid (ASA) works to inhibit the synthesis of thromboxan A2 (TXA2) by inhibiting irreversibly the cyclooxygenase (COX) enzyme. This TXA2 synthesis inhibition results in a reduction of platelet aggregation. However, aspirin is suspected to have many side effects. In the usual dose, the main side effects of aspirin are gastric (intolerance) and gastric and duodenal ulcers [5].

At this time, in the health field there has been a slight paradigm shift. This can be seen from the increased interest in eastern medicine (herbal medicine), from previously dominated by western medicine [6]. Today is

\footnotetext{
Corresponding author: sake.martina@yahoo.com
} 
very widespread use of herbal products that are believed to have more minimal side effects. In recent years there have been many scientific research on herbal products, and not a few of them are proven to have efficacy, not to mention the herbal products that are considered to have antiplatelet effects. Studies have shown that propolis, one of the beekeeping products, has antiplatelet effects [7].

Thus, the above description has inspired the researcher, to do research on the comparison of antiplatelet effects on bee pollen and propolis in this beekeeping product, with aspirin in mice.

\section{Methods}

\subsection{Types and Research Design}

This research is an experimental research with randomized post test design only control group design with single-blind technique. The study used experimental animals that were divided into 4 groups.

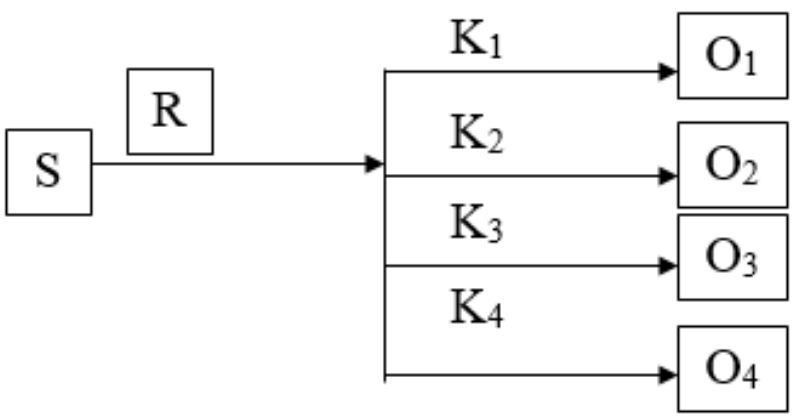

Fig. 1. Types and Research Design

Explanation:

$\mathrm{S} \quad=$ Sample

$\mathrm{R}=$ Randomization

$\mathrm{K} 1=$ Group of control animals (-)

$\mathrm{K} 2$ = Treatment group with oral aspirin for 12 days

$\mathrm{K} 3$ = Treatment group with oral Propolis for 12 days

$\mathrm{K} 4$ = Treatment group by giving Bee Pollen orally for 12 days

$\mathrm{O} 1=$ Control group observation results (-)

$\mathrm{O} 2=$ Observation result of treatment group with aspirin administration

$\mathrm{O} 3$ = Observation result of treatment group with Propolis administration

$\mathrm{O} 4$ = Observation result of treatment group with bee pollen

\subsection{Time and Location of Research}

This research will be conducted in Pharmacology Laboratory of Department of Pharmacology and Therapeutic Faculty of Medicine, University of Sumatera Utara. The study is planned to begin in September - December 2015. Research will be conducted after Ethical Clearance approval from the Ethics Commission of the Faculty of Medicine, University of North Sumatra.

\subsection{Population and Sample Research}

In this study male mice (mus musculus) will be used, Double Distsch Webster strain age: 2-3 months (adult), weight 20-30 grams, healthy, has never been used for other studies. Mice obtained from Laboratorium FMIPA Biologi USU Medan. The number of group try animals is determined by the formula according to Federer (1963), as follows:

$$
(\mathrm{t}-1)(\mathrm{n}-1) \geq 15
$$

Explanation:

$\mathrm{n}=$ sample size

$\mathrm{t}=$ number of groups of experimental animals

Then the required sample size is:

$$
\begin{aligned}
(\mathrm{t}-1)(\mathrm{n}-1) & \geq 15 \\
(4-1)(\mathrm{n}-1) & \geq 15 \\
(\mathrm{n}-1) & \geq 5 \\
\mathrm{n} & \geq 6
\end{aligned}
$$

Based on Federer's formula, it takes a sample of at least 6 animals in each group. With an additional 10\% dropout estimate, the minimum sample size required for each group is 7 experimental animals.

Based on the minimum number of samples allowed statistically and not violating the $3 \mathrm{R}$ (Reduction, Replacement, and Refinement) principle in the experimental animal studies, the number of samples taken into 8 mice for each group. So the total number of animals required is 32 .

The sample selection and clustering were done using simple random sampling, in which 32 samples that met the specified inclusion criteria would be numbered, then divided into 4 groups as large as the computer program (https: // www .randomizer.org /)

\subsection{Criteria for Inclusion, Exclusion and Drop Out}

a. Inclusion Criteria:

1. Mice (mus musculus) strain Double Distsch Webster, male, age: 2-3 months, weight: 20-30 grams.

2. Healthy mice, active movement, and come from the same group.

b. Exclusion Criteria

Previous mice have received drug intervention.

c. Drop out Criteria

Mice die within the study period.

\subsection{Procedure and the Research Flow}

Material taking in this Research the ingredients of beekeeping products used are:

- Aspirin (@BAYER)

- Propolis (@High Desert Indonesia - HDI)

- Bee Pollen (@ High Desert Indonesia - HDI) 


\subsubsection{Preparing and maintaining controlled animal}

Prior to the study, the adaptation of animals at the site with light 12 hours cycle of the dark schedule, the standard diet of eating and drinking ad libitum. The food consumed comes from Charoen Pokhpand. The animals try to be kept at $25 \pm 10{ }^{\circ} \mathrm{C}, 60 \%$ relative humidity. Mice were preserved during the study period, weight was weighed before and after the trial.

\subsection{Procedures}

Male mice (Mus musculus), DDW strain, healthy, body: 20-30 grams, divided into 4 groups:

1. Normal mice as control (-)

2. Mice with aspirin but not given intervention (control + )

3. Mice with oral Propolis per oral for 12 days

4. Mice by giving Bee Pollen orally for 12 days
Mice were administered on the first day of preliminary study for 12 days according to the Conversion Dosage Table.

Dosage:

1. Aspirin: $10.4 \mathrm{mg} / \mathrm{kgBB}$ mice / day

2. Propolis: $65 \mathrm{mg} / \mathrm{kgBB}$ mice / day

3. Bee Pollen: $68 \mathrm{mg} / \mathrm{kgBB}$ mice / day After 12 days, all mice made measurements with Tail Bleeding Method as follows:

1. Clean the area to be incised (tail of mice) with cotton alcohol.

2. First, the tail of the mice is cut using a scalpel and let the blood out freely. When the blood starts out run the stopwatch.

3. Suck the blood out with filter paper / tissue paper every half minute until the blood stops flowing (do not let filter paper / tissue paper touch the wound). Stop the stopwatch when the blood cannot be sucked again. Take note of the time.

Table 1. Dose count conversion (Laurence \& Bacharach, 1964) orally

\begin{tabular}{|l|c|c|c|c|c|c|c|c|}
\hline & Mice 20gram & Mouse200 gr & $\begin{array}{l}\text { Guinea Pig } \\
400 \mathrm{gr}\end{array}$ & Rabbit 1,5 kg & $\begin{array}{l}\text { Cat } \\
2 \mathrm{~kg}\end{array}$ & Monkey 4 kg & $\begin{array}{l}\text { Dog } \\
12 \mathrm{~kg}\end{array}$ & $\begin{array}{l}\text { Human } \\
70 \mathrm{~kg}\end{array}$ \\
\hline $\begin{array}{l}\text { Mice } \\
20 \text { gram }\end{array}$ & 1.0 & 7.0 & 12.25 & 27.8 & 29.7 & 64.1 & 124.2 & 387.9 \\
\hline Mouse 200 gr & 0.14 & 1.0 & 1.74 & 3.9 & 4.2 & 9.2 & 17.8 & 56.0 \\
\hline $\begin{array}{l}\text { Guinea Pig } \\
400 \mathrm{gr}\end{array}$ & 0.08 & 0.57 & 1.0 & 2.25 & 2.4 & 5.2 & 10.2 & 31.5 \\
\hline $\begin{array}{l}\text { Rabbit } \\
1,5 \mathrm{~kg}\end{array}$ & 0.04 & 0.25 & 0.44 & 1.0 & 1.08 & 2.4 & 4.5 & 14.2 \\
\hline $\begin{array}{l}\text { Cat } \\
2 \mathrm{~kg}\end{array}$ & 0.03 & 0.23 & 0.41 & 0.92 & 1.0 & 2.2 & 4.1 & 13.0 \\
\hline $\begin{array}{l}\text { Monkey } \\
4 \mathrm{~kg}\end{array}$ & 0.016 & 0.11 & 0.19 & 0.42 & 0.45 & 1.0 & 1.9 & 6.1 \\
\hline $\begin{array}{l}\text { Dog } \\
12 \mathrm{~kg}\end{array}$ & 0.008 & 0.06 & 0.1 & 0.22 & 0.24 & 0.52 & 1.0 & 3.1 \\
\hline Human 70 kg & 0.0026 & 0.018 & 0.031 & 0.07 & 0.076 & 0.16 & 0.32 & 1.0 \\
\hline
\end{tabular}

\subsection{Data analysis}

The data obtained will be analyzed by ANOVA in the same direction using the computer program when the parametric data is normally distributed. If the data is not normally distributed then the data taken non parametric and tested with Kruskall-Wallis. A difference is significant when $\mathrm{p}<0.05$.

\section{Results}

\subsection{Research result}

\subsubsection{Description on Research Location}

The research was conducted at Pharmacology Laboratory, Department of Pharmacology and
Therapeutic Faculty of Medicine, University of Sumatera Utara (FK USU), Medan. This location is chosen by considering the completeness of facilities and supporting facilities are good enough to support the success of this research. The research was conducted in Pharmacology Laboratory room located on the 1st floor of Pharmacology building, Faculty of Medicine, University of Sumatera Utara. The building of Pharmacology University of North Sumatra is located at University Street No. 1, University of Sumatera Utara Campus, Padang Bulan Village, Medan Baru District, Medan with boundaries:

Northern Limit: Abdul Hakim Building Faculty of Medicine, University of North Sumatra.

Southern Boundary: Department of Nutrition Faculty of Medicine University of North Sumatra 
East Limit: University Road, University Campus of North Sumatra.

West Boundary: Faculty of Nursing University of North Sumatra.

\subsubsection{Sample Characteristics and Descriptive Analysis of Research Results}

In this study, the sample used was 32 male Double Distsch Webster (DDW). Then the sample is divided into 4 groups by simple randomization. The next sample was given different drugs / substances for 12 days. After 12 days, samples were given invasive treatment in the form of cutting the tail and measured bleeding time in seconds. The average time of bleeding data in the placebo group, the group with aspirin, the group with the provision of propolis, and the group with the provision of bee pollen can be seen in Table 2 .

Table 2. Mean Time of Bleeding in Four Sample Groups in Seconds.

\begin{tabular}{|c|r|c|c|}
\hline Samples & Statistic & df & Sig. \\
\hline Placebo & 0,935 & 8 & 0,560 \\
\hline Aspirin & 0,904 & 8 & 0,316 \\
\hline Propolis & 0,910 & 8 & 0,352 \\
\hline Bee Pollen & 0,970 & 8 & 0,896 \\
\hline
\end{tabular}

Based on the results of the study in Table 5.1, the group with the longest bleeding time duration was the group with aspirin administration, i.e. $442.9 \pm 171.9$ seconds. While the group with the average time of the shortest bleeding was the placebo group or group with no administration, which is around $106.1 \pm 33.6$ seconds.

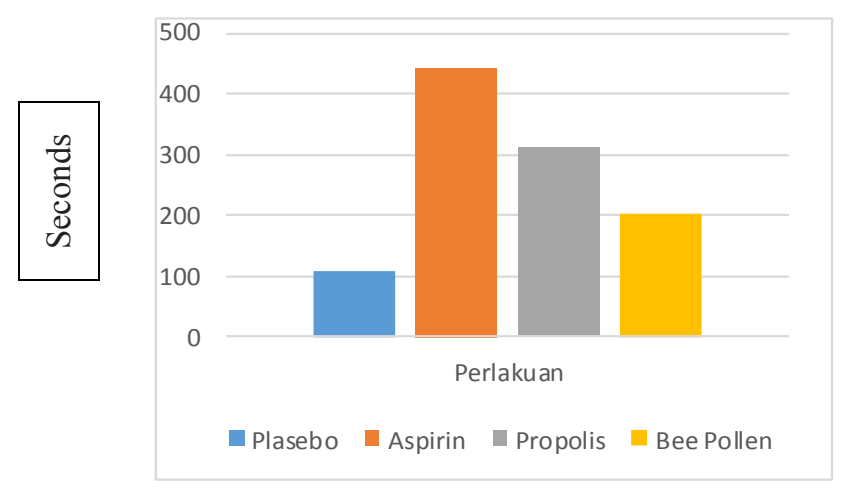

Fig. 2. Time Bleeding Chart with Samples

\subsubsection{Test Data Normality}

In this study, the normality test used is the Shapiro-Wilk test. Data is normally distributed if $p$ value $>0,05$ and is not normally distributed if $p$ value $<0,05$. The results of normality test computations in this study can be seen in table 3 .
Table 3. Data Normality in Four Samples with Shapiro-Wilk Test.

\begin{tabular}{|l|c|c|c|}
\hline \multicolumn{1}{|c|}{ Samples } & N & $\begin{array}{c}\text { Average } \\
\text { Time } \\
\text { Bleeding }\end{array}$ & $\begin{array}{c}\text { Standard } \\
\text { Deviation }\end{array}$ \\
\hline Placebo & 8 & 106,1 second & 33,6 second \\
\hline Aspirin & 8 & 442,9 second & 171,9 second \\
\hline Propolis & 8 & 310,1 second & 91 second \\
\hline Bee Pollen & 8 & 203 second & 67 second \\
\hline
\end{tabular}

Based on computational test results of normality in Table 3.2, the significance value for the placebo group was 0,560 , for the group with aspirin administration of 0.316, for the group with Propolis 0.352, and for the Bee Pollen group of 0.896 . Because the significance value in all four groups is greater than 0.05 , it can be concluded that the data is normally distributed.

\subsubsection{Test Data Homogeneity}

For analysis needs, the data to be analyzed must meet the assumptions underlying ANOVA namely that the variants of some populations are the same (homogeneous). If the significance value is $<0.05$, then it is said that the variant of two or more population data groups is not the same. Whereas if the value of significance $>0.05$, then it is said that the variant of two or more groups of data population is the same (homogeneous). The results of computation homogeneity test in this study can be seen in Table 4 .

Table 4. Homogeneity Data on Four Samples.

\begin{tabular}{|c|c|c|c|}
\hline $\begin{array}{c}\text { Levene } \\
\text { Statistic }\end{array}$ & df1 & df2 & Sig. \\
\hline 2,805 & 3 & 28 & 0,058 \\
\hline
\end{tabular}

Based on the result of computation homogeneity test in the above table, obtained $\mathrm{p}$ value of 0.058 , where $0.058>0.05$. From these results it can be seen that four groups of data population in this study have the same variant (homogeneous) so that it meets the assumptions underlying ANOVA.

\subsubsection{Comparability Test}

Comparability test was aimed to compare the mean time of bleeding in placebo group, group with aspirin, group with Propolis administration, and group with Bee Pollen administration. Based on the normality and homogeneity test, the data in this study are known to be normal distributed and have the same variant (homogeneous), then the comparative analysis used is the test for parametric data that is One Way ANOVA. The results of the analysis with One Way ANOVA test are presented in Table 5. 
Table 5. One Way ANOVA Test Mean Time of Bleeding.

\begin{tabular}{|l|c|c|c|}
\hline \multicolumn{1}{|c|}{ Subject group } & Df & F & Sig. \\
\cline { 1 - 2 } Between group & 3 & \multirow{2}{*}{15,397} & \multirow{2}{*}{0,000} \\
\cline { 1 - 2 } In the group & 28 & & \\
\hline
\end{tabular}

Based on the results in the table above, obtained $\mathrm{p}$ value of 0.000 .

Therefore, it can be concluded that there is a difference of average time of bleeding in all four groups of administration $(\mathrm{p}<0.05)$.

\subsubsection{Advanced Test (Post Hoc Test)}

Because the ANOVA test results show a significant difference, then the next test to see which groups are different. Based on the homogeneity test that has been done before can be seen that the population data group in this study have the same variant, so that the advanced test (Post Hoc Test) used is Bonferroni test. The results of advanced computation tests in this study are presented in Table 6.

Table 6. Bonferroni Advanced Test.

\begin{tabular}{|l|l|c|c|}
\hline $\begin{array}{c}\text { Administration } \\
(\mathbf{X})\end{array}$ & $\begin{array}{c}\text { Administration } \\
(\mathbf{Y})\end{array}$ & $\begin{array}{c}\text { Average } \\
\text { difference } \\
(\mathbf{X}-\mathbf{Y})\end{array}$ & Sig. \\
\hline \multirow{3}{*}{ Placebo } & Aspirin & $-336,750$ & 0,000 \\
& Propolis & $-204,000$ & 0,003 \\
& Bee Pollen & $-96,875$ & 0,442 \\
\hline \multirow{3}{*}{ Aspirin } & Placebo & 336,750 & 0,000 \\
& Propolis & 132,750 & 0,100 \\
& Bee Pollen & 239,875 & 0,000 \\
\hline \multirow{3}{*}{ Propolis } & Placebo & 204,000 & 0,003 \\
& Aspirin & $-132,750$ & 0,100 \\
& Bee Pollen & 107,125 & 0,296 \\
\hline \multirow{2}{*}{ Pollen } & Placebo & 96,875 & 0,442 \\
& Aspirin & $-239,875$ & 0,000 \\
& Propolis & $-107,125$ & 0,296 \\
\hline
\end{tabular}

The results of advanced test computing above show that:

1. The mean time for placebo group bleeding was significantly different with the aspirin group ( $p$ $<0.05$ ) with the mean Aspirin group higher than the placebo group average.

2. Mean time of placebo group bleed differed significantly with the Propolis group $(p<0.05)$ with the Propolis group average higher than the placebo group average.

3. The mean time for placebo group bleeding was not different from Bee Pollen group ( $p>0.05)$ but the mean Bee Pollen group was higher than the placebo group average.

4. Mean time of aspirin group bleeding did not differ from Propolis group ( $>>0,05)$ but mean Aspirin group was higher than mean of Propolis group.

5. Mean time of aspirin group bleed differed significantly with Bee Pollen group $(p<0.05)$ with Aspirin group average higher than mean Bee Pollen group.
6. Mean time of bleeding of Propolis group was not different from Bee Pollen group ( $p>0,05)$ but mean of Propolis group was higher than Bee Pollen mean.

\section{Discussion}

In Table 3.1, the mean bleeding time for the placebo group in this study was $106.1 \pm 33.6$ seconds. The average time bleeding by tail bleeding method in the group of mice who did not receive intervention according to the previous study was 120 seconds [8]. This insignificant difference may be due to the different mice strains used in the previous study using the C57BL / 6 strain, although the weight and age of mice in both studies were within the same range.

In the group with aspirin for 12 days before treatment, the mean time of bleeding was $442.9 \pm 171.9$ seconds and was the highest rate compared to the other three groups. These results are in line with research conducted by Doutremepuich, et al. [9], where the mean time of bleeding in mice with aspirin also experienced statistically significant lengthening, ie $363.3 \pm 93.3$ seconds. This elongation is caused by the mechanism of action of Aspirin, which causes irreversible COX1 inhibition, which further leads to a decrease in the production of TXA2 in platelets. This effect will last for 10 days [10]. Table 3.5 also shows that there was a significant difference between the aspirin group and the placebo group $(p<0.05)$ in which there was an average duration of bleeding in the Aspirin group. This proves the effectiveness of Aspirin as a standard platelet antiaggregation agent.

The mean time of group bleeding with Propolis according to Table 3.1 was $310.1 \pm 91$ seconds. Compared with the placebo group, the mean time of bleeding group of Propolis experienced significant elongation $(p<0.05)$ with a mean difference of 204 seconds. There was also no significant difference between the mean time of group bleeding of Propolis and the mean Aspirin group as standard platelet antiagregation ( $p>0.05)$ with the mean difference of 132.8 seconds as seen in table 3.5. This suggests that in this study, administration of Propolis with a $65 \mathrm{mg} /$ $\mathrm{kgBB}$ dose of mice / day was statistically proven to prolong bleeding time in mice.

The mechanisms underlying the effect of prolongation of bleeding time on Propolis administration have not been ascertained. It is estimated that this effect is mediated by the CAPE contained in Propolis. CAPE enhances the formation of GMP-cyclic which further activates GMP-dependent cyclic phosphorylation of VASP Ser157. Then this sequence of events inhibits the activity of CCP followed by inhibition of phosphorylation of P47 and ultimately inhibition of platelet aggregation [7]. In another study it was mentioned that CAPE specifically inhibited the activation of collagen-induced platelets by interfering with the binding of collagen to its receptor in platelet membranes, eventually lengthening the timing of platelet clogging [11]. Since CAPE involvement in the inhibition of platelet aggregation processes according to some 
studies has varied mechanisms, Propolis is thought to have promising platelet anti-aggregation activity [12].

Further test results in Table 3.5 showed that the mean bleeding time in the Bee Pollen group did not differ significantly between the placebo groups ( $>>0.05)$, although the mean bleeding time in the Bee Pollen group (203 \pm 67 seconds) was still longer than the placebo group average $(106.1 \pm 33.6$ seconds $)$ with a mean difference of 96.9 seconds. Nevertheless, from statistical test results it can be concluded that Bee Pollen administration has no effect on prolongation of bleeding time. This is also consistent with computational results indicating the difference in the average time of bleeding of the Bee Pollen group and the mean Aspirin group ( $p$ $<0.05$ ) as a standard platelet anti-aggregation agent with a mean Aspirin group rate of 239.9 seconds.

Interestingly, in Table 3.5 it can be seen that the mean value of comparison of the average time of bleeding of Bee Pollen group and Propolis group was $0.296(p>0.05)$ with average time of bleeding group of Propolis was higher 107.1 seconds. From previous results it is known that Propolis is proven to prolong bleeding time, so this data indicates the opposite of the previous conclusions. It turned out that giving Bee Pollen may have an effect of prolonged bleeding time in mice because there was no significant difference in the mean time of bleeding in both groups. This is also in accordance with previous studies showing the effect of platelet antiagregation from Bee Pollen. According to research ever conducted, Bee Pollen is known to have a regular content (3,3 ', 4', 5,7-pentahydroxyflavone-3rhamnoglucoside) [13]. Routine antiplatelet activity is obtained by inhibiting the activation of phospholipase $\mathrm{C}$, followed by inhibition of protein kinase $\mathrm{C}$ activity and A2 thromboxane formation which in turn inhibits P47 phosphorylation and intracellular $\mathrm{Ca} 2+$ mobilization, resulting in an inhibitory effect on platelet aggregation [14]. However, according to Komosinska-Vassev, et al., [13] the routine content along with other acids: pantothenic, nicotinic and folate, biotin, and inositol in total only constitute about $0.7 \%$ of Bee Pollen's composition.

In this study, the given Bee Pollen dose was $68 \mathrm{mg} /$ $\mathrm{kgBB}$ mice / day. With relatively fewer routine compositions, higher doses of Bee Pollen may be required to achieve platelet antagonist effects as expected, with a significant difference in mean time of bleeding when compared with the placebo group.

However, further research is needed to determine the effect of platelet antiagregation from Bee Pollen and its therapeutic dose.

\section{Conclusion}

Based on the results of research conducted for Aspirin, Propolis, and Bee Pollen as antiplatelet based on time at the time of mice, it can be concluded as follows:

1. There was a significant difference between the mean time of bleeding in the propolis group and the placebo group $(p=0.003, p<0.05)$ with the average Propolis group higher by 204 seconds. This suggests that statistically provable reflections in mice prior to Propolis administration.

2. The mean bleeding time in the Propolis gifted group was $310.1 \pm 91$ seconds, while the mean time of bleeding in the Aspirin teacher group was $442.9 \pm$ 171.9 seconds. There was no significant number between the mean time of bleeding in both groups ( $p$ $=.100, \mathrm{p}>0.05)$. Thus, the hypothesis of the researcher states that "the time of bleeding in the tail of the mice by administration of propolis longer or equal to aspirin" is acceptable.

3. The mean bleeding time in the Bee Pollen delivery group was $203 \pm 67$ seconds, while the mean time of bleeding in the placebo group was $106.1 \pm 33.6$ seconds. There was no significant figure between the mean time of bleeding in both groups $(\mathrm{p}=0.442, \mathrm{p}>$ 0.05). In this case, the hypothesis of the researcher states that "The time of bleeding in the tail of the mice by giving Bee Pollen longer with the placebo group" is unacceptable. Although not proven statistically different, the mean time of bleeding in the group gave Bee Pollen 96.9 seconds longer than the placebo group rate.

\section{References}

1. Tortora, G. J., Principles of Anatomy and Physiology. 12 ed. Danvers: John Wiley \& Sons, Inc. (2009)

2. World Health Organization, n.d. NCD Mortality and Morbidity. [Online] Available at: http://www.who.int/gho/ncd/mortality_morbidity/e n/ [Accessed 28 May 2015].

3. Peters, R. J. et al., Effects of Aspirin Dose When Used Alone or in Combination with Clopidogrel in Patients with Acute Coronary Syndromes. Circulation, Volume 108, pp. 1682-1687. (2003)

4. Baigent, C., Sudlow, C., Collins, R. \& Peto, R., Collaborative Meta-Analysis of Randomised Trials of Antiplatelet Therapy for Prevention of Death, Myocardial Infarction, and Stroke in High Risk Patients. British Medical Journal, Volume 324, pp. 71-86. (2002)

5. Katzung, B. G. ed., In: Farmakologi Dasar \& Klinik. (Jakarta: Penerbit Buku Kedokteran EGC. 2012)

6. Verkerk, R., Can The Failing Western Medical Paradigm be Shifted Using the Principle of Sustainability. ACNEM Journal, Volume 28, pp. 410. (2009)

7. Chen, T.-G.et al., Antiplatelet Activity of Caffeic Acid Phenethyl Ester is Mediated through a Cyclic GMP-Dependent Pathway in Human Platalets. Chinese Journal of Physiology, 50(3), pp. 121-126. (2007)

8. Liu, Y., Jennings, N. L., Dart, A. M. \& Du, X.-J., Standardizing a simpler, more sensitive and accurate tail bleeding assay in mice. World Journal of Experimental Medicine, 2(2), pp. 30-36. (2012) 
9. Doutremepuich, C., Aguejouf, O., Desplat, V. \& Eizayaga, F. X., Paradoxical Effect of Aspirin. Thrombosis, Volume 2012. (2011)

10. Vane, J. R., Inhibition of prostaglandin synthesis as a mechanism of action for aspirin-like drugs. Nature New Biology, 231(25), pp. 232-235. (1971)

11. Hsiao, G. et al., Vharacterization of a Novel and Potent Collagen Antagonist, Caffeic Acid Phenethyl Ester, in Human Platelets: in vitro and in vivo Studies. Cardiovascular Research, Volume 75, pp. 782-792. (2007)

12. Purohit, A., Joshi, K., Kotru, B. \& Kotru, S., Effect of Indian Propolis on Hematological Parameters in Experimentally Induced Hyperlipidemic Male Albino Rabbits. Asian Journal of Pharmaceutical and Clinical Research, 6(1), pp. 17-19. (2013)

13. Komosinska-Vassev, $\mathrm{K}$. et al., Bee Pollen: Chemical Composition and Therapeutic Application. Evidence-Based Complementary and Alternative Medicine, pp. 1-6. (2015)

14. Sheu, J. R. et al., Mechanisms involved in the antiplatelet activity of rutin, a glycoside of the flavonol quercetin, in human platelets. Journal of Agricultural and Food Chemistry, 52(14), pp. 44144418. (2004) 